\title{
Radiographic Diagnosis of Incipient Proximal Caries: An Ex-Vivo Study
}

\author{
José Moreira da SILVA NETO ${ }^{1}$ \\ Rosenês Lima dos SANTOS ${ }^{2}$ \\ Maria Carmeli Correia SAMPAIO ${ }^{2}$ \\ Fábio Correia SAMPAIO ${ }^{2}$ \\ Isabela Albuquerque PASSOS ${ }^{3}$
}

\author{
${ }^{1}$ Technical School of Health, Health Sciences Center, Federal University of Paraíba, João Pessoa, PB, Brazil \\ ${ }^{2}$ Department of Clinic and Community Dentistry, Health Sciences Center, \\ Federal University of Paraíba, João Pessoa, PB, Brazil \\ ${ }^{3}$ Postgraduate Program in Dentistry, Health Sciences Center, Federal University of Paraíba, João Pessoa, PB, Brazil
}

\begin{abstract}
The aim of this ex vivo study was to compare visual clinical and radiographic examinations to the histological analysis for proximal caries diagnosis in extracted permanent molars and premolars. The relationship between clinical aspects and carious lesions was also evaluated. Eighty-eight proximal surfaces (44 freshly extracted teeth) were longitudinally sectioned with a 370- $\mu$ m diamond disk, thinned with wet silicon carbide paper and observed with a stereomicroscope at $\times 40$ magnification. Sensitivity and specificity were $65.6 \%$ and $83.3 \%$ for clinical examination and $29.7 \%$ and $95.8 \%$ for radiographic examination, respectively. Kappa values ranged from 0.64 to 0.91 . The white spots corresponded to lesions restricted to enamel, while the dark spots corresponded to lesions that reached the dentinoenamel junction. In most cases, cavitation corresponded to dentin lesions. It may be concluded that interproximal radiographic examination is not a reliable method for detection of incipient proximal carious lesions.
\end{abstract}

Key Words: dental caries, clinical examination, radiography, histology.

\section{INTRODUCTION}

Over the years, interproximal radiography has been regarded as an important auxiliary method for proximal caries detection, which provides valuable information for treatment decision (1). However, its accuracy has been questioned due to induction of mistaken diagnosis $(2,3)$ because, in several occasions, radiographs do not detect caries progression and give false negative results (4).

Bille and Thylstrup (2) reported visual diagnosis can be more sensitive than radiography for detection of incipient carious lesions, whereas radiographic diagnosis is rather sensitive for dentinal and cavited lesions. Espelid and Tveit (5) stated that the radiographic examination of deeper and intact surface lesions did not provide an accurate diagnosis with no trustworthy radiographic criteria available to determine the presence of initial or cavited lesions. Although differences between in vivo and in vitro studies have been emphasized (6), histological and stereomicroscopic analyses have been considered the most accurate methods for validation of carious lesions (7).

The widespread use of fluoride has promoted a general caries decline. As a result, accurate caries detection is paradoxically more difficult than before the so-called fluoride era due to the slow caries progression and chances of caries regression (8).

The purpose of the present ex vivo study was to compare visual clinical and radiographic examinations to histological analysis for proximal caries diagnosis in extracted permanent molars and premolars. The relationship between clinical aspects and carious lesions was also evaluated. 


\section{MATERIAL AND METHODS}

\section{Sample Selection}

The sample for this study was composed of 88 proximal surfaces obtained from 44 teeth (22 permanent molars and 22 premolars; sound, with suspected proximal caries or cavited) thad had been freshly extracted due to orthodontic or periodontal reasons. The specimens were kept refrigerated in saline renewed every $72 \mathrm{~h}$ until use. After prophylaxis with water/ pumice slurry and Robinson's bristle brushes, a notch was prepared with a drill on either mesial or distal side, at the root level, in order to distinguish one proximal surface from the other during visual inspection.

\section{Clinical Examination}

Three calibrated examiners performed the visual clinical examination under fluorescent illumination with a Reflex dental focus model (Dabi-Atlante, Ribeirão Preto, SP, Brazil) according to the criteria proposed by Araújo et al. (9): sound, white spot, dark spot, white/ dark spots or cavitation. The teeth were reexamined under the same conditions after $48 \mathrm{~h}$.

\section{Radiographic Examination}

The in vitro interproximal radiographic technique was performed with the aid of an interproximal film-holder, which was attached to the platform of a seriograph using a piece of transparent Scotch tape and rubber strings to ensure that the film was positioned at $90^{\circ}$ in relation to the platform. The indicating cone was placed parallel to the platform at a distance of $100 \mathrm{~mm}$ from the radiographic film, as described by Versteeg et al. (10), with the most central cone portion directed to the film center. A Spectro 70x model x-ray unit (DabiAtlante) operating at $70 \mathrm{KVp}$ and $10 \mathrm{~mA}$ was used.

Before the $\mathrm{X}$-ray incidence, a best-exposure-time checking test was performed to visualize the depth of specific carious lesions in molars and premolars. Exposure times of $0.2,0.3,0.4$ and $0.5 \mathrm{~s}$ were tested with Ektaspeed Plus (EP-21P) films (Eastman Kodak Company, Rochester, NY, USA) that were developed in an A/T 2000 Plus automatic processor (Air Techniques Corp., USA). The 0.5-s exposure time was chosen.

The $\mathrm{x}$-rays incidences were done by adapting a thin articulation wax sheet (Wilson, São Paulo, SP, Brazil) on the bite-wing of the interproximal film-holder, fixing the specimen in such a way that its long axis remained parallel to the radiographic film and the crown turned downwards and the buccal surface remained parallel to the x-ray unit and the roots turned upwards.

After film processing, the radiographs were numbered with a white label and stored in a plastic container. The interproximal radiographs were viewed in a dark environment with the aid of light box with a 30 x $15 \mathrm{~cm}$ screen in bright white resin (Ableh Moldados Termoplásticos Ltda.; Magavision, São Paulo, SP, Brazil), whose light was limited to the radiographic film size by one board paper mask. The same 3 calibrated examiners performed the radiographic examinations. The criteria adopted for radiographic analysis were similar to those proposed in previous studies $(5,11)$ : R0: no visible radiolucency; R1: radiolucency in $1 / 2$ outer enamel; R2: Radiolucency in 1/2 inner enamel up to the dentinoenamel junction(DEJ); R3: Radiolucency in $>1 /$ 3 of outer dentin; R4: Radiolucency in $>2 / 3$ of outer dentin; R5: Radiolucency throughout dentin.

\section{Histological Examination}

The tooth crowns were sectioned longitudinally at the proximal surfaces with a water-cooled low-speed $370-\mu$ m-thick diamond saw (Horico, Berlin, Germany) (12) and the obtained sections were ground flat and hand-polished on wet \#150 silicon carbide paper. Next, the proximal sections were polished with a distilled water/pumice slurry on a glass plate, carefully washed to remove polishing debris and the histological exmaination was performed with an Olympus SZ-40 stereomicroscope (Olympus Inc., Melville, NY, USA) at $\times 40$ magnification, as gold standard (7). The histologist produced the final report, attributing scores to the sections: H0: no proximal carious lesion; H1: carious lesion confined within $1 / 2$ outer enamel; $\mathrm{H} 2$ : carious lesion confined within $1 / 2$ inner enamel up to the DEJ, without reaching dentin; $\mathrm{H} 3$ : carious lesion reaching $>1 / 3$ of outer dentin; H4: carious lesion reaching $>2 / 3$ of outer dentin; $\mathrm{H} 5$ : carious lesion reaching the whole dentin extension.

\section{Statistical Analysis}

In order to obtain the sensitivity and the specificity, the results were categorized as healthy versus 
unhealthy (spotted or cavited) in the clinical examination, $\mathrm{R} 1-\mathrm{R} 5$ versus $\mathrm{R} 0$ in the radiographic examination and $\mathrm{H} 1-\mathrm{H} 5$ versus $\mathrm{H} 0$ in the histological examination.

The adopted histological scores were equivalent to the radiographic ones for the statistical analysis following the guidelines established for data validation used in this research (13). Cohen's Kappa test was employed to check the inter-examiner reproducibility.

\section{RESULTS}

The inter-examiner reproducibility values regarding the radiographic and clinical exams (Kappa's value) were 0.64 and 0.91 , respectively. Data refering to the interactions of the visual clinical, radiographic and histological evaluations are presented in Tables 1-4. The average of the 3 examiners' results were considered for the results of the clinical and radiographic examinations.

Based on the visual clinical examination of the 88 proximal surfaces, $47.3 \%(n=42)$ were considered as sound, while only $27.3 \%(\mathrm{n}=24)$ were scored $\mathrm{H} 0$ by the histological examination. Of the 42 sound surfaces by clinical examination, 22 were classified histologically as $\mathrm{H} 1(\mathrm{n}=15)$ or $\mathrm{H} 2(\mathrm{n}=7)$. Of the 23 surfaces classified as $\mathrm{H} 1,15$ were considered as clinically sound. Of the 24 (27.3\%) classified as H0, 20 were considered as clinically sound and 4 considered as spot lesions (Table 1).

Of the 24 sound surfaces examined histologically, 23 cases were considered to be sound in the radiographic examination and only 1 was scored as R1 based on the adopted radiographic criteria. Of the 68 surfaces classified radiographically as $\mathrm{R} 0,45$ were scored $\mathrm{H} 1$ to $\mathrm{H} 3$, with 23 cases being $\mathrm{H} 1,17$ being $\mathrm{H} 2$ and 5 being $\mathrm{H} 3$. All of the 23 surfaces classified histologically as $\mathrm{H} 1$ were classified radiographically as $\mathrm{R} 0$, while out of the 23 surfaces classified histologically as $\mathrm{H} 2,17$ were scored radiographically as $\mathrm{R} 0$ (Table 2).

Table 3 shows that the

Table 1. Clinical examination data according to the histological examination.

\begin{tabular}{lcccccc}
\hline $\begin{array}{c}\text { Histological } \\
\text { examination }\end{array}$ & \multicolumn{6}{c}{ Clinical examination } \\
\cline { 2 - 7 } & Sound & White spots & Dark spots & Both spots & Cavited & Total \\
\cline { 2 - 7 } & $\%(\mathrm{n})$ & $\%(\mathrm{n})$ & $\%(\mathrm{n})$ & $\%(\mathrm{n})$ & $\%(\mathrm{n})$ & $\%(\mathrm{n})$ \\
\hline H0 & $22.7(20)$ & $8.3(2)$ & $1.1(1)$ & $1.1(1)$ & - & $27.3(24)$ \\
H1 & $17.1(15)$ & $6.8(6)$ & $1.1(1)$ & $1.1(1)$ & - & $26.1(23)$ \\
H2 & $7.9(7)$ & $79.0(7)$ & $9.1(8)$ & $1.1(1)$ & - & $26.1(23)$ \\
H3 & - & $3.4(3)$ & $5.7(5)$ & - & $4.6(4)$ & $13.6(12)$ \\
H4 & - & - & $1.1(1)$ & - & $3.4(3)$ & $4.6(4)$ \\
H5 & - & - & - & - & $2.3(2)$ & $2.3(2)$ \\
Total & $47.7(42)$ & $20.4(18)$ & $18.2(16)$ & $3.4(3)$ & $10.3(9)$ & $100(88)$ \\
\hline
\end{tabular}

percentage of surfaces scored $\mathrm{R} 0$ in the radiographic examination was $77.3 \%(n=68)$, while the percentage of surfaces considered as clinically sound was $47.3 \% \quad(n=42)$. Among the 88 examined surfaces, $92 \%(n=81)$ were classified radiographically as R0 and R1. The smallest percentage $(3.4 \%)$ of visual clinical exams corresponded to both types of spots (Table 3 ).

Data in Table 4 were considered as follows: in the clinical examination - with spot or cavitation (disease) and sound (no disease); in the radiographic examination R1 to R5 (disease) and R0 (no disease); and in the histological exmaination - H1 to H5 (disease) and H0 (no disease).

Table 4 shows that of the histologically positive assessments $65.6 \%$ (sensitivity) were considered to be spotted or cavited as per clinical examination, while of the 24 cases scored histologically as $\mathrm{H} 0,83.3 \%$ (specificity) were considered as clinically sound. 
Regarding the results of the radiographic and histological examinations, out of 64 cases scored histologically from $\mathrm{H} 1$ to $\mathrm{H} 5$, only 19 (sensitivity of $29.7 \%$ ) were scored radiographically from R1 to R5 and 45 (70.3\%) were scored as R0. Of the 24 cases classified as $\mathrm{H} 0,23$ (specificity of 95.8\%) received a R0 radiographic score (Table 4). The analysis of the radiographic versus clinical results shows that of the 20 cases classified from R1 to R5, 18 (90.0\%) were found to be clinically healthy. Of 68 cases scored as R0, 40 $(58.8 \%)$ were considered to be healthy and $28(41.2 \%)$ were believed to have spots or cavitation (Table 4).

\section{DISCUSSION}

The histological examination revealed that nearly half of the surfaces diagnosed as clinically sound showed incipient carious involvement at enamel level under stereomicroscopy that had not been detected during visual inspection. This is an indication that, despite the diagnosis of health/disease, visual examination may not offer fully trustworthy results. Consistently, the histological analysis of surfaces diagnosed clinically as being diseased showed surface alterations in all cases, with a higher trend towards the emergence of dark spots or cavitation, confirming the pattern found by Bille and Thylstrup (2) and Akpata et al. (14).

In the histological examination, carious lesion depth in dentine outer third, when compared to the clinical examination, was the deepest clinical detection limit of white spots. On the other hand, it was the initial histological limit to detect cavitation clinically, suggesting that this may be the limit at which a white spot changes into cavitation. Similar findings have been reported elsewhere (14). Lunder and Fehr's study (11) showed that lesions located in the DEJ were rarely cavited in patients with moderate caries activity. Thus, enamel mineral hardness seems to be an important barrier against cavity formation. When the DEJ is reached, however, the cavitation process is probably speeded up.

Table 3. Clinical examination data according to the radiographic examination.

\begin{tabular}{lcccccc}
\hline $\begin{array}{c}\text { Radiographic } \\
\text { examination }\end{array}$ & $\begin{array}{c}\text { Sound } \\
\%(\mathrm{n})\end{array}$ & $\begin{array}{c}\text { White spot } \\
\%(\mathrm{n})\end{array}$ & $\begin{array}{c}\text { Dark spot } \\
\%(\mathrm{n})\end{array}$ & $\begin{array}{c}\text { Both spots } \\
\%(\mathrm{n})\end{array}$ & $\begin{array}{c}\text { Cavited } \\
\%(\mathrm{n})\end{array}$ & $\begin{array}{c}\text { Total } \\
\%(\mathrm{n})\end{array}$ \\
\cline { 2 - 7 } & & & & & & \\
\hline & $45.4(40)$ & $15.9(14)$ & $11.4(10)$ & $2.3(2)$ & $2.3(2)$ & $77.3(68)$ \\
R0 & $2.3(2)$ & $4.6(4)$ & $3.4(3)$ & $1.1(1)$ & $3.4(3)$ & $14.8(13)$ \\
R2 & - & - & $3.4(3)$ & - & & $3.4(3)$ \\
Total & $47.3(42)$ & $20.4(18)$ & $18.2(16)$ & $3.4(3)$ & $10.2(9)$ & $100.0(88)$ \\
\hline
\end{tabular}

Table 4. Clinical, radiographic and histological results for health/disease assessment. Values are presented as \% (n).

\begin{tabular}{|c|c|c|c|c|}
\hline & \multicolumn{2}{|c|}{ Clinical exam } & \multicolumn{2}{|c|}{ Radiographic exam } \\
\hline & Spot/cavitation $(n=46)$ & Sound $(n=42)$ & R1-R5 (n= 20) & $\mathrm{R} 0(\mathrm{n}=68)$ \\
\hline \multicolumn{5}{|c|}{ Histological exam results } \\
\hline H1 to H5 $(n=64)$ & $65.6(42 a)$ & $34.4(22 d)$ & $29.7(19 a)$ & $70.3(45 d)$ \\
\hline $\mathrm{H} 0(\mathrm{n}=24)$ & $16.7(4 b)$ & $83.3(20 c)$ & $4.2(1 b)$ & $95.8(23 \mathrm{c})$ \\
\hline \multicolumn{5}{|c|}{ Radiographic exam results } \\
\hline $\mathrm{H} 3$ & $90.0(18 a)$ & $10.0(2 \mathrm{~d})$ & - & - \\
\hline $\mathrm{H} 4$ & $41.2(28 b)$ & $58.8(40 \mathrm{c})$ & - & - \\
\hline
\end{tabular}

$\mathrm{a}=$ Positive predictive value $(\mathrm{PV}+) ; \mathrm{b}=$ False-positive $(\mathrm{FP}) ; \mathrm{c}=$ Negative predictive value $(\mathrm{NV}-)$; $\mathrm{d}=$ False-negative $(\mathrm{FN})$. 
When the clinical and histological findings were compared, it was observed that most of the cases were located in the deeper enamel portion $(9.1 \%$ of the sample) and in dentin outer third (5.7\%). However, during the visual clinical examination, no cavitation was detected at the histological enamel levels. During visual inspection, cavitation was observed only when the carious lesion had reached dentin. This result suggests that clinical detection of cavitation on the proximal surface might implicate the need of an invasive procedure due to lesion depth. The location of proximal carious lesions confers a different histological appearance from that of occlusal lesions. In addition, differences in enamel prisms, enamel thickness and cavity shape, as well as access to fluoride and saliva, may slow down or spped up caries progression rates (15).

In this study, most radiographic assessments of the proximal surfaces did not detect carious lesion, but the histological examination detected caries at enamel or at the most external third of dentin. Similar findings have been reported by Pitts and Rimmer (3), supporting the idea that interproximal radiography does not have a high sensitivity (13). In such situation, Araújo et al. (9) stated that some caution is needed, because a more invasive endangerment of the carious lesion may already exist since this was detected in the histological examination.

Radiographically, the proximal carious lesions started being visualized at the level of half the inner enamel, but only in the minority of cases $(6.8 \%)$. This suggests that radiography is not the most indicated method to detect incipient carious lesions confined to enamel, being more effective for lesions that had already reached the DEJ. The radiographic examination had reliable results in two deeper levels of dentin (H4 and $\mathrm{H} 5$ ), indicating that, at these levels, demineralization allows a good radiographic record of radiolucency, as reported in a previous study (2).

Comparing the clinical and radiographic examinations, it was noted that most cases $(45.4 \%)$ were classified as sound and no radiolucency was detected radiographically. Only $2.3 \%$ of the sample showed radiographic image suggestive of caries in enamel, which denotes an agreement between the two methods on the sound surfaces in almost all cases.

As to the surfaces considered to be spotted in the clinical analysis, variations were observed in the radiographic examination, ranging from absence of radiolucency to radiolucency at the DEJ (3.4\%; corresponding to dark spots). However, most spots were not detected radiographically. Only the surfaces clinically diagnosed as cavited were detected in the radiographic image, as observed by Bille and Thylstrup (2). These findings reinforce the importance of interproximal radiography as an auxiliary means to diagnose proximal caries as advocated by Hopcraft and Morgan (1), and also when direct exam by separation with rubbers was used (11).

The clinical examination showed twice as higher sensitivity than the radiographic method in this sample. These data agree with those of Pitts and Rimmer (3) and differed from those of Russel and Pitts (16). Some factors, such as the use of fluoride, might have contributed for these differences $(1,4)$. In contrast, the radiographic method showed higher specificity values than the clinical visual examination. Similar results have been reported by De Vries et al. (17). Based on the results of the present study, it may be inferred that if the radiographic method had a better accuracy for detection of incipient lesions, there would be a stronger trend to classify sound surfaces as without radiolucency, increasing the specificity value, mainly in this low-cariesprevalence sample. In addition, the low Kappa's value observed can be an indication of weakness of the radiographic examination for incipient caries lesions, reinforcing that it should be preferably used as an auxiliary method for diagnosis of proximal caries.

Regarding sensitivity and specificity, comparison of the clinical and radiographic examinations to the histological analysis showed that surfaces diagnosed as having radiolucencies were, in most cases, either spotted or cavited. Also, cases without radiolucencies were considered as healthy clinically in nearly $3 / 5$ of the sample, since a large number of surfaces were lables as caries-free or with incipient carious lesion. This supports the statement that the radiographic examination is more specific than sensitive for samples with low prevalence of caries or with incipient lesions $(3,6)$.

The visual clinical examination seems to be the best method for diagnosis proximal caries. Interproximal radiography is a valuable auxiliary resource for detection of deep proximal dentin carious lesions, but does not reflect the histological aspects of enamel caries. While white spot lesions on proximal surfaces correspond to caries confined to enamel, dark spot lesions correspond to caries at the DEJ level and clinical proximal cavitation is related to deeper dentin caries.

The relevance of this study relies on the fact that, 
together with the recent decline of caries disease, caries detection has become more difficult particularly in proximal surfaces (1). More experienced and skilled professionals are needed to assess caries development accurately and understand the restorative decision-making process. Although already explored in the literature, this issue is still under discussion in several areas of Dentistry.

In addition to proximal radiography, high-technology caries detection methods with higher sensitivity than radiography have been investigated, such as DIAGNOdent, Ultrasound Caries Detector and Digora (18-20). However, the sensitivity of these methods is roughly similar to that of radiography and thus their still high costs do not justify their purchasing by the clinician. Despite the availability of different caries detection methods, none of them present high sensitivity values. From the clinical point of view, this is an indication that the best caries detection approach still relies on a combination of techniques allied to the dentist's knowledge and clinical judgment. In conclusion, the results of the present study indicate that bite-wing radiography is not a trustworthy method for detection of proximal incipient carious lesion, but it can of great value for the diagnosis of cavited carious lesions, mainly dark spots.

\section{RESUMO}

Este estudo ex vivo comparou os exames visual e radiográfico com a análise histológica no diagnóstico de cárie interproximal em pré-molares e molares permanentes extraídos. Também foi avaliada a relação entre os aspectos clínicos e as lesões de cárie. Para tanto, 88 superfícies proximais (de 44 dentes recém-extraídos) foram seccionadas longitudinalmente com um disco diamantado de 370 $\mu \mathrm{m}$, polidas com lixas abrasivas e observadas em estereomicroscópio com aumento de $\times 40$. A sensibilidade e especificidade dos exames clínico e radiográfico foram $65,6 \%$ e $83,3 \%$, e $29,7 \%$ e $95,8 \%$, respectivamente. O índice de Kappa variou de 0,64 a 0,91 . As manchas brancas corresponderam a danos em esmalte, enquanto as manchas escuras corresponderam à profundidade da junção amelo-dentinária. As cavitações clínicas corresponderam a lesões em dentina, na maioria dos casos. Concluise que o exame radiográfico interproximal nãoé um método confiável para descoberta clínica de lesões de cáries proximais incipientes.

\section{REFERENCES}

1. Hopcraft MS, Morgan MV. Comparison of radiographic and clinical diagnosis of approximal and occlusal dental caries in a young adult population. Community Dent Oral Epidemiol 2005;33:212-218.

2. Bille J, Thylstrup A. Radiographic diagnosis and clinical tissue changes in relation to treatment of approximal carious lesions. Caries Res 1982;16:1-6.
3. Pitts NB, Rimmer PA. An in vivo comparison of radiographic and directly assessed clinical caries status of posterior approximal surfaces in primary and permanent teeth. Caries Res 1992;26:146-152.

4. Creanor SL, Russell, Strang DM, Stephen KW, Burchell CK. The prevalence of clinically undetected occlusal dentine caries in Scottish adolescents. Braz Dent J 1990;169:126-129.

5. Espelid I, Tveit AB. Clinical and radiographic assessment of approximal carious lesions. Acta Odontol Scand 1986;44:31-37.

6. Van Rijkom HM, Verdonschot EM. Factors involved in validity measurements of diagnostic tests for approximal caries - a meta-analysis. Caries Res 1995;29:364-370.

7. Hintze H, Wenzel A, Larsen MJ. Stereomicroscopy, film radiography, microradiography and naked-eye inspection of tooth sections as validation for occlusal caries diagnosis. Caries Res 1995;29:359-363.

8. Fejerskov O. Changing paradigms in concepts on dental caries: consequences for oral health care. Caries Res 2004;38:182-191.

9. Araújo FB, Rosito DB, Toigo E, dos Santos CK. Diagnosis of approximal caries: radiographic versus clinical examination using tooth separation. Am J Dent 1992;5:245-248.

10. Versteeg KH, Sanderink GC, Velders XL, Van Ginkel FC, Van der Stelt PF. In vivo study of approximal caries depth on storage phosphor plate images compared with dental x-ray film. Oral Surg Oral Med Oral Pathol Oral Radiol Endod 1997;84:210-213.

11. Lunder N, Fehr FR von der. Approximal cavitation related to bite-wing image and caries activity in adolescents. Caries Res 1996;30:143-147.

12. Ekstrand KR, Ricketts DNJ, Kidd EAM. Reproducibility and accuracy of three methods for assessment of demineralization depht on the occlusal surface: an in vitro examination. Caries Res 1997;31:224-231.

13. Anderson M, Stecksén-Blicks C, Stenlund H, Ranggård L, Tsilingaridis G, Mejàre I. Detection of approximal caries in 5-year-old swedish children. Caries Res 2005;39:92-99.

14. Akpata ES, Farid MR, al-Saif K, Roberts EA. Cavitation at radiolucent areas on proximal surfaces of posterior teeth. Caries Res 1996;30:313-316.

15. Kidd EA, Banerjee A, Ferrier S, Longbottom C, Nugent Z. Relationships between a clinical-visual scoring system and two histological techniques: a laboratory study on occlusal and approximal carious lesions. Caries Res 2003;37:125-129.

16. Russell M, Pitts NB. Radiovisiographic diagnosis of dental caries: initial comparison of basic mode videoprints with bite-wing radiography. Caries Res 1993;27:65-70.

17. De Vries HC, Ruiken HM, Konig KG, Van't Hof MA. Radiographic versus clinical diagnosis of approximal caries lesions. Caries Res 1990;24:364-370.

18. Lussi A, Hack A, Hug I, Heckenberger H, Megert B, Stich H. Detection of approximal caries with a new laser fluorescence device. Caries Res 2006;40:97-103.

19. Matalon S, Feuerstein O, Calderon S, Mittleman A, Kaffe I. Detection of cavited carious lesions in approximal tooth surfaces by ultrasonic caries detector. Oral Surg Oral Med Oral Pathol Oral Radiol Endod 2007;103:109-113.

20. Wenzel A, DrOdont, Haiter-Neto F, Gotfredsen E. Influence of spatial resolution and bit depth on detection of small caries lesions with digital receptors. Oral Surg Oral Med Oral Pathol Oral Radiol Endod 2007;103:418-422.

Accepted March 13, 2008 